\title{
A Study On Factors Affecting Outcome In Endoscopic Dacryocystorhinostomy
}

\author{
Dr. Vivek Kumar Pathak ${ }^{(1),}$ Dr.(Prof.) Debajit Das ${ }^{[2],}$ Dr.Uttal Taranga Bhuyan ${ }^{(3)}$ \\ Dr.Pinpo Teron ${ }^{(4)}$ \\ Corresponding author ${ }^{(l)}$, M.S.(ENT), PGT, department of otorhinolaryngology, Assam Medical College, \\ Dibrugarh, Assam-786001,Phone no.-91-9435332629,Fax no.-013342720732, \\ Prof. and Head ${ }^{(2)}$,Assoc. Prof. ${ }^{(3)}$,Assist. Prof ${ }^{(4)}$,department of otorhinolaryngology, Assam Medical College , \\ Dibrugarh , Assam
}

\section{Introduction:}

Dacryocystorhinostomy (DCR) is a procedure that involves creating a passage of lacrimal sac into nose bypassing nasolacrimal (nld) blockage , Lacrimal sac can be approached by (1)External (2)Endoscopic approach,Endoscopic DCR is a safe,fast ,aesthetic and effective method to relieve a stenosis distal to common canaliculus . External DCR first described by Toti in $1904^{[1,2]}$,Endonasal approach was first described by Caldwell in $1893^{[2,3]}$. Fiberoptic endoscope first used for Endo-DCR by Mc Dough \& Miring in $1989^{[4]}$. Endoscopic approach has renewed interest in past decade to correct primary and recurrent lacrimal obstruction ,This study was carried to evaluate the success of Endo-DCR with patient point of view of acceptability, In addition to find out preoperative and intraoperative factors that affect the outcome in endoscopic DCR .

\section{Materials And Methods:}

This study was conducted in department ototorhinolaryngology,AMCH,Dibrugarh,Assam ,Type of study:Prospective ,intervention study ,During period of study from May 2011 to April 2012, a total of 38 cases reported in ENT department ., All the cases were examined by ROPLAS regurgitation test,syringing , probing ,DNE , Only 30 cases were having nasolacrimal duct obstruction and common canalicular obstruction so they were included into study, Inclusion criterion: All cases irrespective of age,sex having

Epiphora, Acute on chronic dacryocystitis, Chronic daryocystitis following nld ,cc block, Exclusion criterion: Suspicion of malignancy, Post traumatic lid and bony deformity, Noticeable lid laxity, No. of cases: 30 cases were included in the study as par inclusion criterion in all the cases detailed clinical examination, Nasal endoscopy, X-ray PNS was done, All the cases underwent endoscopic dacryocystorhinostomy under local anaesthesia \& medical treatment pre and postoperative, Follow up was done in all cases at regular interval of 1 week,2weeks,3weeks,6weeks,3months and 6months. Following parameters were studied(1) Subjective improvement of symptoms :

Fully satisfied

Partially satisfied

Not satisfied at all

2) Anatomical Patency By Syringing

3) Duration of symptoms

4) History of previous surgical intervention .

5)Age

6)Sex

7)Presence /Absence of Pre-operative deviated nasal septum .

8) Presence/ Absence of excessive intra-operative bleeding .

Data were analysed by Graphpad for microsoft version 6.01, chi square test with Yates correction was applied for comparison between groups . P value of $<0.05$ was considered stastically significant .

\section{Results And OBSERVATIONS :}

A total of 30 patients comprising $(22$ females[33.33\%] \& 8[26.67\%] were enrolled in study, Mean age was 32.03 yrs. range(18-51 yrs.)

(1) Subjective Improvement Of Symptoms:

Fully Satisfied : $20(66.67 \%)$ cases, Partially Satisfied : 2 (6.67\%) case, ,No Improvement : $8(26.67 \%)$ cases

(2) Anatomical patency by Syringing :

Anatomical Success : 24 (80\%) cases

Failure $\quad: \quad 6(20 \%)$ cases 


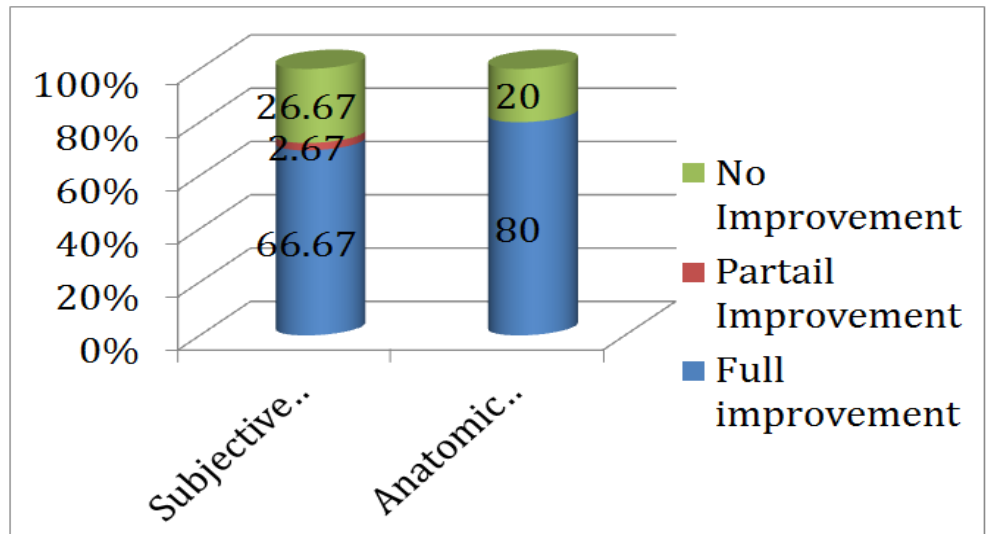

TABLE I ; SHOWING OUTCOME ACCORDING TO DURATUON OF SYMPTOM \& PREVIOUS SURGICAL INTERVENTION:

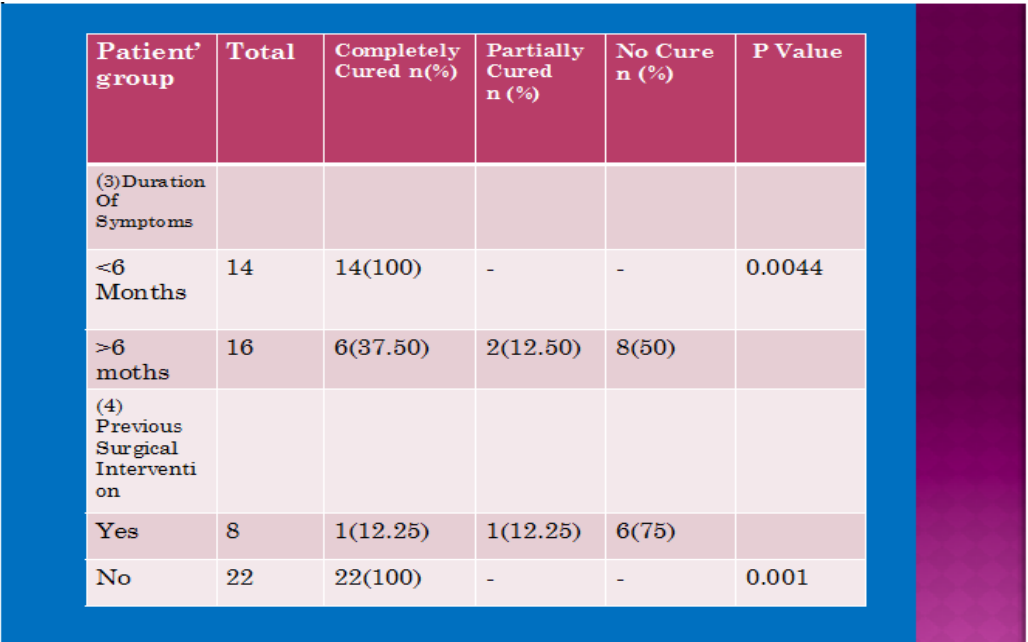

TABLE II : SURGICAL OUTCOME ACCORDING TO AGE

\begin{tabular}{|l|l|l|l|l|}
\hline $\begin{array}{l}\text { Age Group (in } \\
\text { years) }\end{array}$ & $\begin{array}{l}\text { Total No. Of } \\
\text { Cases n }(\%)\end{array}$ & $\begin{array}{l}\text { Success } \\
\mathbf{n}(\%)\end{array}$ & $\begin{array}{l}\text { Failure Cases n } \\
(\%)\end{array}$ & P Value \\
\hline $0-20$ & $3(10)$ & $3(100)$ & 0 & 0.59 \\
\hline $21-30$ & $8(16.67)$ & $6(75)$ & $2(25)$ & \\
\hline $31-40$ & $12(40)$ & $8(66.67)$ & $4(33.34)$ & \\
\hline $41-50$ & $5(16.67)$ & $3(60)$ & $2(40)$ & \\
\hline $51-60$ & $2(6.67)$ & $2(100)$ & 0 & \\
\hline
\end{tabular}

TABLE III : OUTCOME ACCORDING TO SEX

\begin{tabular}{|l|l|l|l|l|}
\hline SEX & $\begin{array}{l}\text { NO. OF CASES } \\
\text { n }(\%)\end{array}$ & $\begin{array}{l}\text { SUCCESS } \\
\text { CASES } n(\%)\end{array}$ & $\begin{array}{l}\text { FAILURE CASE } \\
\text { n(\%) }\end{array}$ & P Value \\
\hline FEMALE & $22(73.33)$ & $16(72.72)$ & $6(27.28)$ & 1.0 \\
\hline MALE & $8(26.67)$ & $6(75)$ & $2(25)$ & \\
\hline TOTAL & 30 & 22 & & \\
\hline
\end{tabular}


TABLE IV : OUTCOME ACCORDING TO PREOPERATIVE DEVITED SEPTUM

\begin{tabular}{|c|c|c|c|c|}
\hline $\begin{array}{l}\text { SEPTAL } \\
\text { DEVIATION }\end{array}$ & $\begin{array}{l}\text { TOTAL NO. } \\
\text { OF CASES } \\
\text { N }(\%)\end{array}$ & $\begin{array}{l}\text { SUCCESS } \\
\text { CASES n }(\%)\end{array}$ & $\begin{array}{l}\text { FAILURE } \\
\text { CASES n }(\%)\end{array}$ & $\begin{array}{l}\text { P } \\
\text { VALUE }\end{array}$ \\
\hline PRESENT & $8(26.67)$ & $2(25)$ & $6(75)$ & 0.03 \\
\hline ABSENT & $22(73.34)$ & $20(90.90)$ & $2(9.10)$ & \\
\hline
\end{tabular}

TABLE V : OUTCOME ACCORDING EXCESSIVE INTRAOPERATIV BLEEDING

\begin{tabular}{|l|l|l|l|l|}
\hline $\begin{array}{l}\text { EXCESSIVE } \\
\text { BLEEDING }\end{array}$ & $\begin{array}{l}\text { TOTAL NO. OF } \\
\text { CASES } \mathbf{n}(\%)\end{array}$ & $\begin{array}{l}\text { SUCCESS } \\
\text { CASES n }(\%)\end{array}$ & $\begin{array}{l}\text { FAILURE CASES } \\
\mathbf{n}(\%)\end{array}$ & P value \\
\hline PRESENT & $5(16.67)$ & $2(40)$ & $3(60)$ & 0.1 \\
\hline ABSENT & $25(83.34)$ & $20(80)$ & $5(20)$ & \\
\hline
\end{tabular}

\section{Discussion :}

In our study $66.67 \%$ patients were fully satisfied,6.67\% partially satisfied with surgery which is supported by study of Tripathi et al ${ }^{(5)}$ fully satisfied $60.86 \%$,partailly satisfied $39.14 \%$, In our study $80 \%$ patients were anatomically patent on syringing which is supported by study of Tripathi et al ${ }^{(5)} 90 \%$ anatomically patent, In our study $100 \%$ success was achieved in $<6$ months duration of symptpms and $37.50 \%$ in $>6$ months with P value 0.0044 which was stastically significant which is supported by study of Tripath ${ }^{(5)} 96 \%$ success was achieved in <6months, Previous Surgical Intervention : In our study 100\% success was achieved when no previous surgical intervention was present while $12.25 \%$ success rate was achieved when previous surgical intervention was present with $\mathrm{P}$ value 0.001 which was statically significant which is supported by study of Tripathi et al ${ }^{(5)}, 89 \%$ success was achieved when no previous surgical intervention was present, Recurrence was found more in51-60years age group (50\%) $\mathrm{P}$ value 0.01 which is supported by study of Tripathi et $\mathrm{al}^{(5)}$ 'females (27.28\%) P value 0.9 , having septal deviation(75\%) Pvalue0.03 which is statically significant, Excessive intraoperative bleeding $(60 \%) \mathrm{P}$ value 0.1 , In our study excessive intraoperative bleeding $(60 \%)$ was a cause of failure this is supported by studies of ,Nishi Gupta ${ }^{(6)}$.

\section{Conclusion;}

The present study clearly shows that Endoscopic DCR is well tolerated and recommended by the patients, Younger patients, with no previous surgical intervention and with short duration of symptoms are likely to benefit most .

Success rate can increased by correction of DNS at same sitting and intra-operative control of bleeding effectively, further research is required

[1]. Toti A ; Clin. Moderna,Firenze 1904,10:385-387.

\section{References}

[2]. Caldwell GW:Two new operations for obstruction of the nasolacrimal duct, NYJ Med 1893,57;581-582 .

[3]. Allen KM, Berlin AJ: Dacryocystorhinostomy failure: association with nasolacrimal silicon intubation Ophthalmic surgery 1989, 20 ;486-489.

[4]. Sprekelsen MB ,Barberan MT.Endoscopic dacryocystorhinostomy : surgical techniques and results.Laryngoscope 1996;106,187-189.

[5]. Tripathi et al. Local anaesthetic Endonasal endoscopic LASER DCR analysis of patients acceptability and various factors affecting the success of the procedure.

[6]. Nishi Gupta. Endoscopic Dacryocystorhinostomy : A Revolution, $2^{\text {nd }}$ edition 